\title{
Marketing Strategy for Education Services in Integrated Islamic- Based Junior High Schools
}

\author{
Desi Afriwanti ${ }^{1 凶}$, Himyar Pasrizal ${ }^{2}$ \\ Manajemen Pendidikan Islam, Institut Agama Islam Negeri Batusangkar, Indonesiaa, \\ email: afriwanti6@gmail.com ${ }^{1}$, himyarpasrizal@iainbatusangkar.ac.id ${ }^{2}$
}

DOI: $10.31958 /$ jies.v1i2.3022

\begin{tabular}{|c|c|}
\hline Article info & Abstract \\
\hline Article History & $\begin{array}{l}\text { The study aims to describe the strategy and marketing mix of education services in } \\
\text { Integrated Islamic Junior High School (SMP-IT). The researcher used qualitative }\end{array}$ \\
\hline Recieved: & research to describe the data descriptively. Data collection techniques were \\
\hline 06/03/2021 & observation, interviews, and documentation. The results of this study indicated \\
\hline Accepted: & that: 1) the marketing strategy in SMP-IT is to strengthen the IT and Public \\
\hline $17 / 11 / 202121$ & Relations (Humas) team in the school. 2) The marketing strategy of education \\
\hline Published: & services in SMP-IT is by implementing a marketing mix of products, prices, places, \\
\hline $30 / 11 / 2021$ & $\begin{array}{l}\text { promotions, human resources, physical evidence and processes. The superior } \\
\text { marketed products are tahfiz programs, language programs, Birrul Walidain and }\end{array}$ \\
\hline 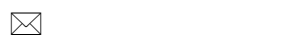 & academic extracurriculars, as well as providing scholarship for excellent students. \\
\hline Corresponding author & $\begin{array}{l}\text { Promotion strategies are carried out through Instagram, YouTube, Twitter, } \\
\text { Facebook, websites, and newspapers.. }\end{array}$ \\
\hline
\end{tabular}

Keywords: Marketing Strategy for Education Services, Integrated Islamic Junior High School, Marketing Mix.

\begin{abstract}
Abstrak
Tujuan penelitian ini untuk untuk mendeskripsikan strategi dan bauran pemasaran jasa pendidikan di Sekolah Menengah Petama Berbasis Islam Terpadu (SMP-IT). Jenis penelitian yang penulis gunakan adalah penelitian kualitatif dengan pendekatan deskriptif. Teknik pengumpulan data yang penulis gunakan yaitu observasi, wawancara dan dokumentasi. Hasil penelitian ini menunjukan bahwa:1) strategi pemasaran yang di gunakan oleh Sekolah Menengah Pertama Islam Terpadu (SMP-IT) dengan memperkuat tim IT dan Hubungan Masyarakat (Humas) yang ada disekolah. 2) strategi pemasaran jasa pendidikan di SMP-IT dilaksanakan melalui penerapan Marketing mix produk, harga, tempat, promosi, sumber daya manusia, bukti fisik dan proses. Produk unggulan yang di pasarkan berupa program tahfiz, program berbahasa, Birrul Walidain dan ektrakurikuler Akademik, serta memberikan potongan beasiswa kepada anak-anak yang berprestasi. Strategi promosi dilakukan melalui instagram, youtube, twitter, facebook, website, surat kabar.
\end{abstract}

Kata kunci: Strategi Pemasaran Jasa Pendidikan, SMP IT, Marketing Mix 


\section{PENDAHULUAN}

Pada zaman dewasa ini lembaga pendidikan di tuntut untuk dapat mampu bersaing dengan baik untuk memenuhi atau bahkan melebihi keinginan dan kebutuhan masyarakat sebagai konsumen jasa pendidikan dengan melakukan perbaikan secara terus menerus dalam semua aspek pendidikan untuk meningkatkan kualitas pendidikan (Wahyudi, 2017; Warmansyah, 2020a). Persaingan dalam dunia pendidikan tidak dapat di hindari lagi, banyak lembaga pendidikan yang kurang di minati, bahkan di tinggalkan karena tidak sesuai dengan keinginan pelanggan (Labaso, 2019). Hasil penelitian yang dilakukan oleh Agus R \& Ummah, (2019) menemukan bahwa kemampuan administrator dalam memahami pemasaran pendidikan menjadi prasyarat dalam mempertahankan dan meningkatkan mutu lembaganya.

Pemasaran merupakan salah satu fungsi strategis yang dalam suatu lembaga dalam menjalankan aktivitas pendidikannya, terutama saat persaingan dalam dunia pendidikan menunjukkan intensitas semakin tinggi (Munir, 2018). Hal tersebut sejalan dengan yang disampaikan oleh Fradito et al., (2020), menyebutkan bahwa pemasaran merupakan ujung tombak bagi eksistensi lembaga pendidikan dalam jangka panjang. Banyak lembaga pendidikan yang tinggalkan oleh pelanggan karena gagal dalam melaksanakan pemasarannya secara efektif (Haryanto \& Rozza, 2020). Rancangan pemasaran tidak hanya berpusat pada barang habis saja, namun juga mengarah pada jangka panjang yang menekankan kepada kepuasan pengguna, pemasaran yang efektif dapat mempertemukan antara lembaga pendidikan dan pelanggannya, baik secara langsung maupun melalui pasar perantara (Ulum, 2018).

Penelitian ini mengkaji strategi pemasaran yang di lakukan oleh SMP-IT Insan Cendekia Boarding School Payakumbuh di era globalisasi yang semakin kompetitif. Penelitian ini di pandang penting, untuk menjadi rujukan dan sekaligus model pemasaran jasa pendidikan pada lembaga pendidikan umum lainya baik itu lembaga pendidikan umum swasta maupun Negeri dan lembaga pendidikan islam swasta maupun Negeri, kaitannya dengan usaha untuk menjawab tantangan dan tuntutan globalisasi saat ini. Hal ini penting untuk membangun kepercayaan diri lembaga pendidikan untuk menciptakan pendidikan umum berbasis keagamaan yang tidak kalah hebatnya dengan lembaga pendidikan islam pada umumnya

Lembaga pendidikan SMP IT Insan Cendekia Boarding School merupakan salah satu sekolah swasta yang banyak di minati dan menarik perhatian masyarakat karena pendidikannya yang unggul dan memiliki banyak prestasi, tidak hanya di bidang akademik akan tetapi juga bidang non akademik. Sekolah ini mampu menumbuhkan minat masyarakat di atas rata-rata sekolah swasta lainya, bahkan yang lebih menarik adalah bahwa peminatnya bukan hanya berasal dari wilayah dimana sekolah tersebut berdiri melainkan juga berasal dari berbagai daerah seperti sumatera Barat,Sumatera Utara, Riau, Jambi, Bengkulu, Sumatera Selatan, Kalimantan, Sulawesi, Jakarta, Nusa Tenggara Barat dan ada juga yang berasal dari luar Negeri yakni Malaysia dan Jepang 
SMP IT Insan Cendekia Boarding School Payakumbuh memiliki programprogram yang bagus, sarana prasarana yang cukup lengkap dan guru yang berkompeten di bidangnya hal ini terbukti dengan prestasi yang diraih oleh sekolah baik prestasi guru maupun prestasi siswa dan hal ini yang membuat sekolah ini mampu merekrut para peserta didik untuk bersekolah didik karena memang sekolah ini layak untuk dimasuki. Dan prestasi ini menjadi salah satu alat untuk pemasaran sekolah yang nantinya akan mereka upload ke sosial media sekolah yang nantinya akan dilihat oleh masyarakat untuk menyekolahkan anak-anak mereka di sekolah ini. Dalam hal ini sekolah harus selalu melakukan inovasi-inovasi baru terkait dengan pelaksanaan pemasaran sekolah agar bisa meningkatkan jumlah peserta didik setiap tahunnya.

\section{Tabel 1.}

\section{Jumlah Peserta Didik SMP -IT Insan Cendekia Boarding School Payakumbuh}

\begin{tabular}{lll}
\hline No & Tahun Ajaran & Jumlah peserta didik \\
\hline $\mathbf{1}$ & Tahun 2016-2017 & 891 Orang \\
\hline $\mathbf{2}$ & Tahun 2017-2018 & 1197 Orang \\
\hline $\mathbf{3}$ & Tahun 2018-2019 & 1007 Orang \\
\hline $\mathbf{4}$ & Tahun 2019-2020 & 969 Orang \\
\hline
\end{tabular}

(Sumber: Profil SMP- IT Insan Cendekia Boarding School Payakumbuh 2019)

Berdasarkan data di atas dapat di katakan bahwa SMP IT insan cendekia Boarding School mampu menumbuhkan minat dan kepercayaan masyarakat untuk menyekolahkan anaknya di SMP IT insan cendekia Boarding School. Hal ini di buktikan dengan meningkatnya jumlah peminat yang ingin bersekolah di sana, namun pada tahun ajaran 2018/2019 dan 2019/2020 sekolah hanya menerima sedikit siswa. Hal ini di karenakan sudah ada peraturan dari pusat bahwa jumlah siswa yang ada di dapodik di batasi, di mana kelas maksimal hanya boleh 33 rombongan belajar. jadi kesimpulannya pada tahun ajaran2018/2019 dan 2019/2020 SMP-IT hanya bisa menerima 6 kelas saja. Hal ini bukan berarti jumlah siswa mereka berkurang akan tetapi memang sekolah ini mengurangi jumlah siswa yang akan di terima karena sudah ada peraturan dari pusat bahwa data yang ada di dapodik di kurangi.

Berdasarkan keunikan dari sekolah SMP IT tersebut yang memiliki daya tampung siswa yang selalu tercukupi setiap tahunnya ditambah animo para orang tua yang ingin putra-putrinya bersekolah di lembaga tersebut, maka penelitian ini bertujuan untuk menggali strategi pemasaran jasa pendidikan yang diterapkan oleh Sekolah Menengah Terpadu (SMP-IT).

\section{METODE PENELITIAN}

Jenis penelitian yang peneliti gunakan adalah jenis penelitian lapangan dengan menggunakan metode deskriptif kualitatif yaitu berupa mengungkapkan serta menggambarkan kembali kejadian yang terjadi di lapangan (Raco, 2018). Kejadian yang 
terjadi adalah mengenai Strategi Pemasaran Jasa Pendidikan Di SMP-IT Insan Cendekia Boarding School Payakumbuh. Lokasi penelitian yaitu di SMP-IT Insan Cendekia Boarding School Payakumbuh yang beralamat di Padang Kaduduak. Teknik pengumpulan data dilakukan melalui wawancara yang peneliti lakukan dengan kepala sekolah, waka humas, kepala Tata Usaha, Wali murid, serta salah satu siswa.

Analisis data dilakukan pertama mulai dari data yang sudah terkumpul, lalu direduksi dan ditarik kesimpulan (Yuliani, 2018). Setelah itu penyajian data dengan cara menyusun sekumpulan data. Selanjutnya, menghubungkan dan membandingkan antara teori yang ada dengan hasil praktik di lapangan (Fachrudin, 2013). Teknik pemeriksaan keabsahan data dalam penelitian ini menggunakan teknik triangulasi data. Teknik triangulasi data yang dilakukan dengan cara membandingkan dan mengecek derajat kepercayaan informan (Bachri, 2010).

\section{HASIL DAN PEMBAHASAN}

Penelitian ini melibatkan sumber informan dari SMP-IT Insan Cendekia Boarding School Payakumbuh antara lain kepala sekolah, waka humas, kepala Tata Usaha, Wali murid, serta salah siswa. Informan tersebut dijadikan sebagai sumber informasi untuk mengetahui strategi pemasaran jasa pendidikan di SMP-IT insan Cendekia Boarding School Payakumbuh. Data penelitian strategi pemasaran jasa pendidikan ini diperoleh menggunakan instrumen pengumpulan data berupa wawancara, dokumentasi dan observasi.

\section{Strategi Pemasaran Jasa Pendidikan Di SMP-IT Insan Cendekia Boarding School Payakumbuh}

Berdasarkan hasil penelitian yang penulis lakukan temukan bahwa proses pemasaran yang di lakukan oleh pihak sekolah SMP -IT Insan Cendekia Boarding School Payakumbuh yakni dilakukan secara reguler yakni dengan mempublikasikan prestasiprestasi yang ada disekolah dan momentum acara tertentu yang ada disekolah. Selain itu dalam melakukan pemasaran sekolah juga menggunakan Program ICBS Go To School, dimana dalam Program ini para murid yang pulang atau libur di wajibkan untuk datang ke sekolah mereka yang lama untuk mempromosikan sekolah dengan cara mengajarkan metode Tahfiz yang Vocabulary bahasa inggris selama 15 menit didepan kelas dan juga program Birrul Waladin yakni siswa di wajibkan menolong orang tua mereka kemudian orang tua murid mendokumentasikan semua kegiatan yang di lakukan oleh anak mereka kemudian nanti baru akan di kirim kepada tim humas sekolah. Dan proses pemasaran yang di lakukan oleh pihak sekolah SMP-IT Insan Cendekia Boarding School Payakumbuh yakni dilakukan secara reguler yakni dengan mempublikasikan prestasiprestasi yang ada disekolah dan momentum acara tertentu yang ada disekolah. 


\section{Strategi Bauran Pemasaran (Marketing Mix) Yang Di Terapkan di SMP-IT Insan Cendekia Boarding School Payakumbuh}

Strategi tersendiri yang dimiliki untuk mempromosikan sekolah mereka yaitu dengan menerapkan strategi bauran pemasaran jasa pendidikan yang penjabarannya sebagai berikut:

\section{Strategi Produk SMP -IT Insan Cendekia Boarding School Payakumbuh}

Pertama Intrakurikuler, mempunyai tenaga pendidik dan yang profesional dalam menyampaikan ilmunya sesuai dengan bidangnya masing-masing, meskipun guru-guru disana belum berstatus sebagai PNS akan tetapi mereka mampu mengasah anak didik mereka sehingga mereka memiliki prestasi di berbagai bidang dan adanya program pendukung seperti wajib tinggal di asrama dan terbina selama 24 jam di bawah bimbingan para ustadz dan ustazah, wajib menggunakan bahasa arab dan bahasa inggris dalam berkomunikasi sehari-hari, baik di dalam maupun di luar kelas, berdisiplin dalam segala hal sesuai dengan ketentuan masing-masing. Kedua Program Unggulan. SMP-IT insan Cendekia Boarding School Payakumbuh mempunyai beberapa program unggulan yaitu Tahfidz Qur'an, English Camp, Arabic Camp, pembinaan MTQ, pembinaan Olimpiade. Dari beberapa program unggulan tersebut program tahfiz yang menonjol karena terbukti dari berbagai prestasi yang di raih oleh para santri baik di tingkat SMP maupun tingkat SMA bahkan sudah sampai ke tingkat Nasional dan secara pelaksanaanya memang di sediakan waktu khusus untuk program tahfiz ini. Ketiga Program Reguler seperti khidmah Ijtimaiyyah, dimana kegiatan ini dilaksanakan setiap akhir pekan, dimana para siswa secara bergantian berkunjung ke sebuah masjid di pemukiman penduduk untuk memakmurkan masjid disana, studi komparative keluar negeri, Rihlah Edukatif, Profession Day, Student Day, Market Day, dan Birrul walidin. Keempat Program Ektrakurikuler, seperti program berbahasa, Halaqah Tarbiyah, Pembinaan olimpiade Sains, Studi komperatif, Rihlah, Edukatif, Muhadharah, dan, beberapa, Ektrakurikuler seperti, pramuka, paskibraka, olahraga (badminton, vollyball, renang, futsal, basket, catur, tenis meja), bengkel Sastra (cerpen, puisi, drama), bengkel Seni (seni lukis, kaligrafi, tari, dan lain-lain), bela diri (tapak suci, taekwondo, dan lain-lain), Multimedia(graphic design, audio visual, dan lain-lain), jurnalistik dan photograpi, bulan sabit merah remaja (BSMR), Training For Trainer (ToT).

\section{Strategi Harga}

Strategi harga yang di lakukan oleh SMP-IT Insan Cendekia Boarding School adalah dengan memberikan beasiswa bagi anak-anak yang berprestasi, namun ada juga beasiswa yang dikhususkan bagi anak-anak yatim dan anak-anak yang kurang mampu prosedur pelaksanaannya di lakukan seleksi khusus oleh tim dalam rangka menyeleksi anak-anak yang memang layak di berikan keringanan biaya pendidikan. Hal ini sejalan dengan penelitian yang dilakukan oleh Faizin (2017), menemukan bahwa strategi harga membuat pengguna menjadi tertarik dalam memasukkan putra-putrinya terutama dengan adanya diskon yang diberikan bagi calon murid yang berprestasi. 


\section{Strategi Lokasi SMP -IT Insan Cendekia Boarding School Payakumbuh}

Secara garis besar sekolah memiliki tampilan yang mempunyai kemudahan dalam akses lokasi. SMP-IT insan Cendekia Boarding School Payakumbuh atau yang biasa dikenal dengan ICBS memiliki dua jenjang pendidikan yaitu SMP dan SMA. ICBS memiliki tiga lokasi terpisah, kampus putra yang beralamat di padang kaduduak, kelurahan tigo koto diateh, kecamatan Payakumbuh utara, kota Payakumbuh, kampus putri beralamat di jalan tan malaka KM 4 parit lubuak aie kecamatan lamposi tigo nagari, sedangkan kampus tiga beralamat di jorong lubuak limpato kawasan wisata harau, kabupaten 50 kota. SMP-IT Insan Cendekia Boarding School (ICBS) Payakambuh memiliki lokasi yang aman dan nyaman dari kebisingan, karena memliki lokasi yang jauh dari pusat kota, sehingga anak-anak merasa nyaman dan tenang dalam mengikuti pembelajaran dan sekolah memiliki strategi tersendiri agar para murid dan orang tua wali murid merasa nyaman dengan pelayanan yang sekolah berikan.

\section{Strategi Promosi SMP IT-Insan cendikia Boarding School Payakumbuh}

SMP- IT Insan Cendekia Boardig School Payakumbuh melakukan promosi dengan 2 cara yaitu promosi yang dilakukan secara langsung dan tidak langsung.1) Promosi secara langsung yaitu para ustadz melakukan kunjungan secara langsung ke SD negeri maupun swasta yang bertujuan untuk mempromosikan pihak SMP- IT insan cendekia Boarding School Payakumbuh kepada siwa-siswa siswi agar mereka tertarik dan melanjutkan ke pihak SMP- IT insan cendekia Boarding School Payakumbuh. Program ICBS go to School yang mana para peserta didik mengunjungi sekolah mereka terdahulu untuk mengenalkan sekaligus mengajarkan metode tahfiz dan vocabulary bahasa inggris kepada anak-anak di sekolah yang mereka kunjungi tersebut, kemudian guru di minta untuk mengambil vidio yang nantinya akan di kemas oleh tim humas untuk dijadikan ajang promosi bahwa anak-anak tampil di sekolah dan serentak di lakukan oleh seluruh alumni di seluruh Indonesia. Program Birrul Walidain yaitu kegiatan yang mewajibkan seluruh siswa untuk membantu orang tua mereka selama berada di rumah dan kemudian nanti orang tua mereka akan membuat video dan mengirim kepada pihak sekolah dan ini yang nantinya akan di upload oleh sekolah ke sosial media sekolah yang akan di lihat oleh masyarakat dan tentu saja masyarakat akan tertarik untuk menyekolahkan anaknya di sana. Promosi melalui media online seperti website (http:www.icbsPayakumbuh.sch.id), facebook (Insan Cendekia Boarding School Payakumbuh), instagram (@icbs_Payakumbuh), twitter (icbs_Payakumbuh), melalui channel Youtube (ICBS TV) radio, berisi fakta-fakta seperti lokasi, prestasi siswa, guru, kegiatan siswa dan lain sebagainya. Mempromosikan sekolah dengan cara ikut serta di berbagai ajang perlombaan yang diadakan oleh pihak-pihak tertentu yang lingkupnya tingkat provinsi maupun tingkat nasional. Mempromosikan sekolah melalui media cetak yaitu brosur, pamplet, banner yang dalam hal ini mendapat dukungan langsung dari yayasan karena menyediakan iklan prabayar di media cetak yang sewaktu-waktu tertentu 
di pakai satu halaman khusus untuk promosi sekolah.2) Promosi secara tidak langsung yaitu mempererat tali silaturahmi dengan masyarakat melalui kegiatan pemberian sumbangan-sumbangan kepada masyarakat dan juga melibatkan siswa dalam berbagai kegiatan kemasyarakatan seperti jika ada orang meninggal di sekitar sekolah para ustadz dan sebagian santri juga ikut serta dalam penyelenggaraan jenazah, pada saat bulan Ramadhan para siswa diminta untuk menyalurkan paket Ramadhan yang diberikan keluarga kurang mampu di sekitar sekolah dan kegiatan-kegiatan lain yang menyangkut dengan promosi sekolah.

\section{Strategi orang (people) SMP-IT Insan Cendekia Boarding School Payakumbuh}

Sumber daya manusia di SMP -IT Isan cendekia Boarding School payakambuh, ICBS selalu melakukan evaluasi setiap minggunya bahkan jika ada perubahan jadwal mereka tetap melakukan evaluasi, tujuannya adalah untuk memberikan kenyamanan kepada para konsumen atau peserta didik bahkan orang tua peserta didik sekalipun. Dan mereka juga mempunyai program yaitu mengadakan pelatihan bahasa inggris bagi para karyawan khusus, tujuannya adalah untuk memberikan pelayanan kepada orang tua murid yaitu sekolah mendatangkan guru dari luar untuk melatih para karyawan khususnya dalam berbahasa inggris. Selain itu mereka juga memiliki program pelatihan atau training bagi guru-guru secara berkala, mengikutsertakan guru dalam kegiatan MGMP, mengikutsertakan guru dan pegawai dalam kegiatan seminar, simposium, diskusi atau dialog, dan kemudian mengadakan studi banding ke sekolah-sekolah lain.

\section{Strategi bukti fisik SMP-IT Insan Cendekia Boarding School Payakumbuh}

Hal yang menunjang untuk proses pembelajaran oleh SMP-IT Insan Cendekia Boarding School Payakumbuh diantaranya adalah keadaan bukti fisik yang di miliki. Adapun bukti fisik yang di miliki oleh SMP-IT ICBS adalah kantor yayasan, ruang guru, ruang tata usaha, ruang kepala sekolah, perpustakaan, UKS, ruang aula, mesjid, ruang asrama. Bukti fisik yang menarik sangat mendukung proses pemasaran dalam mempengaruhi konsumen para pelanggan jasa pendidikan. Fasilitas yang nyaman merupakan salah satu pemasaran yang sangat menarik (Warmansyah, 2020b).

\section{Strategi Proses SMP-IT Insan Cendekia Boarding School Payakumbuh}

Dalam proses pembelajaran SMP-IT Insan cendekia Boarding School Payakumbuh memliki strategi untuk meningkatkan kualitas dari para peserta didik yaitu dengan menerapkan berbagai macam metode pembelajaran yaitu learning system yang mereka gunakan lebih banyak ke blendid system artinya mereka mencampur antara di dalam dan di luar jaringan (Perdana, 2019). Hal yang paling utama bagi para guru memadukan nilai-nilai Islam dengan nilai-nilai pembelajaran sesuai dengan mata pelajaran yang di berikan kepada para siswa dan sekolah juga menggunakan kurikulum yang memadukan kurikulum nasional dan kurikulum unggulan yang diadopsi dari sekolah unggulan baik di dalam maupun di luar negeri. Dalam program peningkatan 
prestasi akademik adalah pembelajaran yang bermutu, melaksanakan bimbingan belajar khusus pada mata pelajaran tertentu sesuai dengan kebutuhan siswa (Muslimin, 2020), dalam program peningkatan prestasi non akademik strategi yang dilakukan sekolah adalah menjaring siswa yang berbakat dan melaksanakan kegiatan latihan ekstrakurikuler. Selain itu SMP-IT Insan cendekia Boarding School Payakumbuh meningkatkan kualitas dari para guru dan karyawan langkah yang diambil oleh sekolah yaitu dengan melaksanakan pelatihan/training guru secara berkala, mengikutsertakan guru dalam kegiatan MGMP, mengikutsertakan guru dan pegawai dalam kegiatan seminar, simposium, diskusi atau dialog dan kemudian mengadakan studi banding ke sekolah-sekolah lain. pembinaan santri di asrama mendapatkan perhatian penuh dari pihak yayasan insan cendekia Boarding School Payakumbuh. Sementara itu untuk meningkatkan kualitas sumber daya manusia para pembinaan asrama terus di tingkatkan melalui pelatihan secara berkala maupun bentuk-bentuk peningkatan kualitas lainnya.

Secara garis besar hasil penelitian yang telah didapatkan melalui proses wawancara dan observasi menunjukkan bahwa Pemasaran adalah suatu proses sosial dan manajerial yang di dalamnya individu dan kelompok untuk mendapatkan apa yang mereka butuhkan dan apa yang mereka inginkan melalui penciptaan, penawaran dan pertukaran atau dapat juga di sebut sebagai kegiatan manusia yang di arahkan untuk memenuhi dan memuaskan kebutuhan dan keinginan melalui proses pertukaran (Syamsul Arifin, 2020). Menurut Philip Kotler dalam bukunya manjemen pemasaran, pemasaran bersandar pada konsep inti berikut: kebutuhan (needs), keinginan (wants), dan permintaan (demands), produk (barang, jasa dan gagasan, nilai budaya, kepuasan, pertukaran dan transaksi, hubungan dan jaringan, pasar serta pemasar dan calon pelanggan (Kurniyati, 2011).

Hasil penelitian yang didapatkan bahwa SMP-IT Insan Cendekia Boarding School Payakumbuh dalam melakukan promosi sekolah di bidang IT juga melaksanakan program yaitu dengan melaksanakan kegiatan road show atau di sebut juga dengan ICBS Go To School, di mana para murid di wajibkan untuk datang ke sekolah mereka yang lama untuk mempromosikan sekolah sekaligus mengajarkan metode tahfidz dan vocabulary bahasa inggris kepada anak-anak yang berada di sekolah mereka yang lama. Dan juga program birrul walidin yaitu kegiatan yang mewajibkan seluruh sisa untuk membantu orang tua mereka selama berada di rumah dan kemudian nanti orang tua merek akan membuat vidio dan mengirim kepada pihak sekolah dan ini yang nantinya akan diupload oleh sekolah ke sosial media sekolah yang akan di lihat oleh masyarakat dan tentu saja masyarakat akan tertarik untuk menyekolahkan anaknya di sana.

\section{KESIMPULAN}

Secara umum, pemasaran jasa pendidikan di SMP-IT Insan Cendekia Boarding School Payakumbuh menggunakan teori Marketing Mix sebagai alat pemasarannya yang terdiri dari produk, harga, lokasi, promosi, sumber daya manusia, bukti fisik, proses. Adapun hasil penelitian yang dilakukan di SMP-IT Insan Cendekia Boarding School 
Payakumbuh, diketahui bahwa SMP-IT Insan Cendekia Boarding School Payakumbuh dapat menjadi model penerapan teori Marketing Mix sebagai strategi pemasaran jasa pendidikan swasta lainnya agar lebih berkembang dan menciptakan inovasi-inovasi baru seperti yang dilakukan oleh yayasan insan cendekia Boarding School Payakumbuh.

\section{DAFTAR PUSTAKA}

Agus R, A. H., \& Ummah, B. (2019). Strategi Image Branding Universitas Nurul Jadid di Era Revolusi Industri 4.0. Tarbiyatuna: Jurnal Pendidikan Islam, 12(1), 59. https://doi.org/10.36835/tarbiyatuna.v12i1.352

Bachri, B. S. (2010). Meyakinkan Validitas Data Melalui Triangulasi Pada Penelitian Kualitatif. Teknologi Pendidikan, 10(1), 46-62.

Fachrudin, Y. (2013). Analisis Penelitian Kualitatif. Universitas Islam Negeri Syarif Hidayatullah Jakarta, 5-10.

Faizin, I. (2017). Strategi pemasaran jasa pendidikan dalam meningkatkan nilai jual madrasah. $\quad$ Madaniyah, $7(2), \quad 261-283$. https://journal.stitpemalang.ac.id/index.php/madaniyah/article/view/75

Fradito, A., Suti'ah, \& Muliyadi. (2020). Strategi Pemasaran Pendidikan Dalam Meningkatkan Citra Sekolah. Al-Idarah: Jurnal Kependidikan Islam, 10(1), 12-22.

Haryanto, R., \& Rozza, S. (2020). Pengembangan Staretegi Pemasaran dan Manajemen Hubungan Masyarakat dalam Meningkatkan Peminatan Layanan Pendidikan. Ekonomi Dan Bisnis, 11(1), 27-34.

Kurniyati, N. N. (2011). Penanggulangan Kemiskinan Melalui Pemberdayaan Masyarakat pada Sektor Industri Genteng Studi di Desa Margoluwih, Kecamatan Seyegan, Kabupaten Sleman, Provinsi DIY. Akmenika UPY, 7, 1-25.

Labaso, S. (2019). Penerapan Marketing Mix sebagai Strategi Pemasaran Jasa Pendidikan di MAN 1 Yogyakarta. Manageria: Jurnal Manajemen Pendidikan Islam, 3(2), 289-311. https://doi.org/10.14421/manageria.2018.32-05

Munir, M. (2018). Manajemen Pemasaran Pendidikan Dalam Meningkatkan Kuantitas Peserta Didik. Intizam: Jurnal Manajemen Pendidikan Islam, 1(2), 78-94.

Muslimin, M. (2020). Program Penilaian Kinerja Guru dan Uji Kompetensi Guru dalam Meningkatkan Prestasi Kerja Guru. Indonesian Journal of Education Management \& Administration Review, 4(1), 193-200.

Perdana, E. S. (2019). Blended Learning: Transisi Pembelajaran Konvensional Menuju Online. Prosiding Seminar Nasional Fakultas Ilmu Sosial Universitas Negeri Medan, 3, 855-860.

Raco, J. (2018). Metode penelitian kualitatif: jenis, karakteristik dan keunggulannya. https://doi.org/10.31219/osf.io/mfzuj 
Syamsul Arifin. (2020). Marketing Pendidikan. Tadris : Jurnal Penelitian Dan Pemikiran Pendidikan Islam, 14(1), 112-123. https://doi.org/10.51675/jt.v14i1.75

Ulum, M. (2018). Konsep Pemasaran Lembaga Pendidikan dalam Pandangan Syariah. Studi Islam, 5(2), 30-42.

Wahyudi, K. (2017). Manajemen Pemasaran Pendidikan. Kariman, 05(01), 65-82.

Warmansyah, J. (2020a). Program Intervensi Kembali Bersekolah Anak Usia Dini Masa Pandemi Covid-19. Jurnal Obsesi : Jurnal Pendidikan Anak Usia Dini, 5(1), 743. https://doi.org/10.31004/obsesi.v5i1.573

Warmansyah, J. (2020b). Supervisi Akademik Kepala Sekolah Taman Kanak-kanak Dimasa Pandemi Covid 19. Tadbir : Jurnal Studi Manajemen Pendidikan, 4(2), 175. https://doi.org/10.29240/jsmp.v4i2.1695

Yuliani, W. (2018). Metode Penelitian Deskriptif Kualitatif dalam Perspektif Bimbingan dan Konseling. Quanta, 2(2), 83-91. https://doi.org/10.22460/q.v1i1p1-10.497 